\title{
Epstein-Barr virus LMP2A signaling in statu nascendi mimics a B cell antigen receptor-like activation signal
}

\author{
Niklas Engels ${ }^{1 *}$, Gökhan Yigit ${ }^{1}$, Christoph H Emmerich ${ }^{1}$, Dirk Czesnik², Detlev Schild ${ }^{2}$ and Jürgen Wienands ${ }^{1 *}$
}

\begin{abstract}
Background: The latent membrane protein (LMP) 2A of Epstein-Barr virus (EBV) is expressed during different latency stages of EBV-infected B cells in which it triggers activation of cytoplasmic protein tyrosine kinases. Early studies revealed that an immunoreceptor tyrosine-based activation motif (ITAM) in the cytoplasmic N-terminus of LMP2A can trigger a transient increase of the cytosolic $\mathrm{Ca}^{2+}$ concentration similar to that observed in antigenactivated B cells when expressed as a chimeric transmembrane receptor. Even so, LMP2A was subsequently ascribed an inhibitory rather than an activating function because its expression seemed to partially inhibit B cell antigen receptor (BCR) signaling in EBV-transformed B cell lines. However, the analysis of LMP2A signaling has been hampered by the lack of cellular model systems in which LMP2A can be studied without the influence of other EBV-encoded factors.

Results: We have reanalyzed LMP2A signaling using B cells in which LMP2A is expressed in an inducible manner in the absence of any other EBV signaling protein. This allowed us for the first time to monitor LMP2A signaling in statu nascendi as it occurs during the EBV life cycle in vivo. We show that mere expression of LMP2A not only stimulated protein tyrosine kinases but also induced phospholipase C- $\gamma 2$-mediated $\mathrm{Ca}^{2+}$ oscillations followed by activation of the extracellular signal-regulated kinase (Erk) mitogen-activated protein kinase pathway and induction of the lytic EBV gene bzlf1. Furthermore, expression of the constitutively phosphorylated LMP2A ITAM modulated rather than inhibited $\mathrm{BCR}$-induced $\mathrm{Ca}^{2+}$ mobilization.

Conclusion: Our data establish that LMP2A expression has a function beyond the putative inhibition of the BCR by generating a ligand-independent cellular activation signal that may provide a molecular switch for different EBV life cycle stages and most probably contributes to EBV-associated lymphoproliferative disorders.
\end{abstract}

Keywords: B Cells, Epstein-Barr virus, LMP2A, B cell antigen receptor, ITAM, tyrosine phosphorylation, $\mathrm{Ca}^{2+}$, latency, lytic replication

\section{Background}

A common feature of herpes viruses is their ability to maintain latent infections during which no virus particles are produced. The oncogenic Epstein-Barr virus (EBV) establishes such a latent infection in human B cells [1]. At least four different types of EBV latency have been described based on the expression patterns of EBV genes including those encoding latent membrane

\footnotetext{
* Correspondence: nengels@gwdg.de; jwienan@uni-goettingen.de 'Institute of Cellular and Molecular Immunology, Georg-August-University Göttingen, Humboldtallee 34, Göttingen 37073, Germany Full list of author information is available at the end of the article
}

protein (LMP) 1 and 2A [2]. The lipid raft-resident LMP2A contains 12 transmembrane domains and both, the $\mathrm{N}$ - and $\mathrm{C}$-terminus face the cytosol. An immunoreceptor tyrosine-based activation motif (ITAM) in the LMP2A N-terminus is constitutively phosphorylated and activates the protein tyrosine kinase (PTK) Syk [3]. This enables LMP2A to support development and maintenance of peripheral B cells in LMP2A transgenic mouse models $[4,5]$. We have previously shown that for these purposes LMP2A also employs the intracellular adapter protein SLP65 (BLNK or BASH), which is a key effector molecule of the $\mathrm{B}$ cell antigen receptor (BCR) [6].
C Biomed Central 
Following engagement of the BCR, SLP65 in conjunction with the adaptor CIN85 nucleates assembly of the $\mathrm{Ca}^{2+}$ initiation complex comprising Bruton's tyrosine kinase (Btk) and phospholipase C (PLC)- $\gamma 2[7,8]$.

So far, the standard model system for biochemical analysis of LMP2A signaling mechanisms was based on EBV-transformed primary human B cells known as lymphoblastoid cell lines (LCL), which express, however, several EBV gene products. Although early studies demonstrated that the LMP2A ITAM in the context of chimeric transmembrane proteins activates the $\mathrm{Ca}^{2+}$ initiation complex, experiments using LCL suggested that LMP2A acts as inhibitor of BCR-induced activation signals and prevents mobilization of $\mathrm{Ca}^{2+}$ ions from intra- and extracellular sources $[3,9,10]$. This observation led to the hypothesis that LMP2A suppresses viral replication which would be induced upon BCR activation of LMP2A-negative cells [11]. However, recent studies showed that constant activation of BCR-regulated signaling pathways - as done by LMP2A - induces and maintains BCR unresponsiveness resulting in B cell anergy $[12,13]$. To circumvent this problem and to analyze LMP2A signaling in statu nascendi in non-anergic cells in the absence of any other EBV gene product, we now established a Cre/loxP-based system to inducibly express LMP2A in B cells. We show that expression of LMP2A not only activated PTKs but also the $\mathrm{Ca}^{2+}$ initiation complex resulting in oscillatory $\mathrm{Ca}^{2+}$ fluxes similar to those observed after BCR stimulation. This triggered activation of the mitogen-activated protein kinase (MAPK) pathway as well as the expression of EBV-encoded BZLF1, the master regulator of lytic EBV replication. In addition, the constitutively phosphorylated LMP2A ITAM modulated BCR-induced $\mathrm{Ca}^{2+}$ mobilization. Our results show that similar to the antigen-activated BCR, induction of LMP2A expression can trigger the lytic EBV replication cycle in an ITAMdependent manner. In contrast to the BCR, however, the LMP2A activation signal does not require extracellular ligation.

\section{Results}

Online monitoring of LMP2A signaling events using the cre/loxP recombination system

In order to investigate the signaling capacity of LMP2A in statu nascendi during the first hours following its expression in the absence of other EBV-encoded molecules, we employed the Cre/loxP recombination system to express LMP2A in an inducible manner in DT40 B cells (for details see Methods and [14]). Briefly, treatment of the cells with 4-hydroxytamoxifen (4-HT) triggered Cre-mediated excision of a loxP site-flanked puromycin resistance cassette from the LMP2A expression vector (Figure 1A). This deletion brings the $\operatorname{lmp} 2 a$ cDNA under transcriptional control of a promotor. Anti-FLAG immunoblotting showed that LMP2A expression was detectable $4 \mathrm{~h}$ upon 4-HT treatment and increased thereafter (Figure 1B). A maximum was reached after an induction period of 12 to $24 \mathrm{~h}$. Beyond this time, the amount of LMP2A declined continuously and was barely detectable after $48 \mathrm{~h}$ (data not shown). The exact molecular mechanisms that shut down LMP2A expression remain to be elucidated but this phenomenon could possibly explain why the generation of B cell transfectants that stably produce significant amounts of LMP2A is hardly feasible (data not shown). As shown in Figures $1 \mathrm{C}$ and 1D, induced expression of LMP2A activated PTKs and triggered phosphorylation of LMP2A itself as well as cellular substrates including the known downstream effectors Syk and SLP65 [3,6]. The increasing intensities of the anti-phosphotyrosine signals correlated with the amount of LMP2A protein, indicating that different LMP2A expression levels quantitatively and perhaps qualitatively regulate B cell signaling as suggested by Casola et al. [5]. Notably, the overall tyrosine phosphorylation pattern was very similar to that obtained upon BCR stimulation of LMP2A-negative control cells. Thus, mere expression of LMP2A is sufficient to constitutively activate $B$ cell signaling cascades that are normally under BCR control.

Early studies reported that when expressed in the context of chimeric transmembrane proteins the LMP2A ITAM required extracellular cross-linking to activate PTKs and subsequent $\mathrm{Ca}^{2+}$ mobilization $[15,16]$. However, in those experiments the ITAM-containing $\mathrm{N}$-terminus of LMP2A having a type-II like membrane topology was fused to type-I transmembrane proteins whereby its physiological orientation was inverted. To address a possible influence of the membrane topology on the need for extracellular ligation we analyzed the LMP2A N-terminus in the context of a type-I or a type-II transmembrane protein, respectively (see Figure 2A). Expression of a type-I CD8/LMP2A fusionprotein indeed required extracellular cross-linking to stimulate protein tyrosine phosphorylation (Figure 2B) and subsequent $\mathrm{Ca}^{2+}$ mobilization (Figure 2C). In contrast - but similar to wild-type LMP2A - expression of the LMP2A N-terminus in the context of the type-II transmembrane protein CD72 caused the constitutive phosphorylation of intracellular signaling proteins which was not enhanced upon extracellular ligation (Figure 2D). In line with our experiences gained with wild-type LMP2A expression of the chimeric CD72/LMP2A fusionprotein could only be achieved using our conditional expression system (see Figure 1A and data not shown) which strengthens the notion that expression of a constitutively firing ITAM-containing receptor is not tolerated by DT40 B cells. 

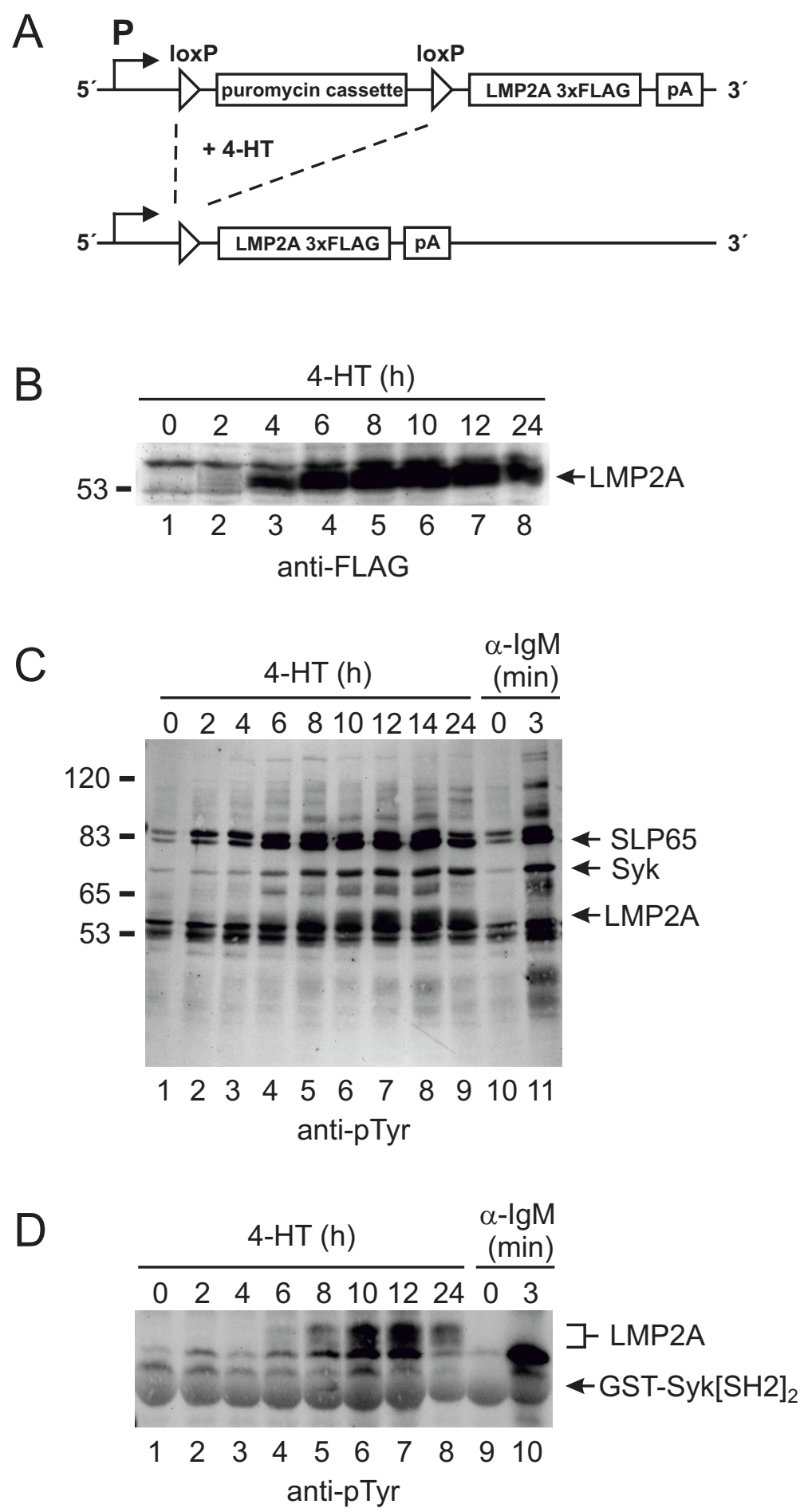

Figure 1 Induced expression of LMP2A in DT40 B cells causes PTK substrate phosphorylation. (A) LMP2A expression strategy. Treatment of DT40 transfectants with 4-HT induces Cre-mediated excision of a loxP-flanked puromycin resistance cassette which otherwise prevents the promotor (P) from activating transcription of a CDNA encoding triple-FLAG-tagged LMP2A (LMP2A3XF). (B), Following 4-HT treatment for the indicated time points, expression of LMP2A3xF was monitored on the protein level by anti-FLAG immunoblotting of cellular lysates. (C) LMP2A transfectants of DT40 B cells were treated with 4-HT for the indicated times (lanes 1-9), left untreated (lane 10) or stimulated for 3 min with antiIgM antibodies (lane 11). Upon lysis, tyrosine-phosphorylated proteins were purified using anti-phosphotyrosine antibodies (covalently coupled to NHS-Sepharose) and subjected to anti-phosphotyrosine (anti-pTyr) immunoblotting. Relative molecular masses of marker proteins are indicated on the left in $\mathrm{kDa}$. (D) The same cells as before were treated with 4-HT for the indicated times (lanes 1-8), left untreated (lane 9) or stimulated for 3 min with anti-IgM antibodies (lane 10). After lysis in 1\% NP40-containing lysis buffer, tyrosine-phosphorylated proteins were affinity purified using a fusion protein consisting of GST and the tandem SH2 domains of Syk (GST-Syk[SH2 $]_{2}$ ). The GST-Syk[SH2 $]_{2}$ fusion protein specifically binds to doubly phosphorylated ITAM motifs. Purified proteins were subjected to anti-phosphotyrosine immunoblotting. The positions of phosphorylated LMP2A and the (non-phosphorylated) GST fusion protein are indicated on the right. 


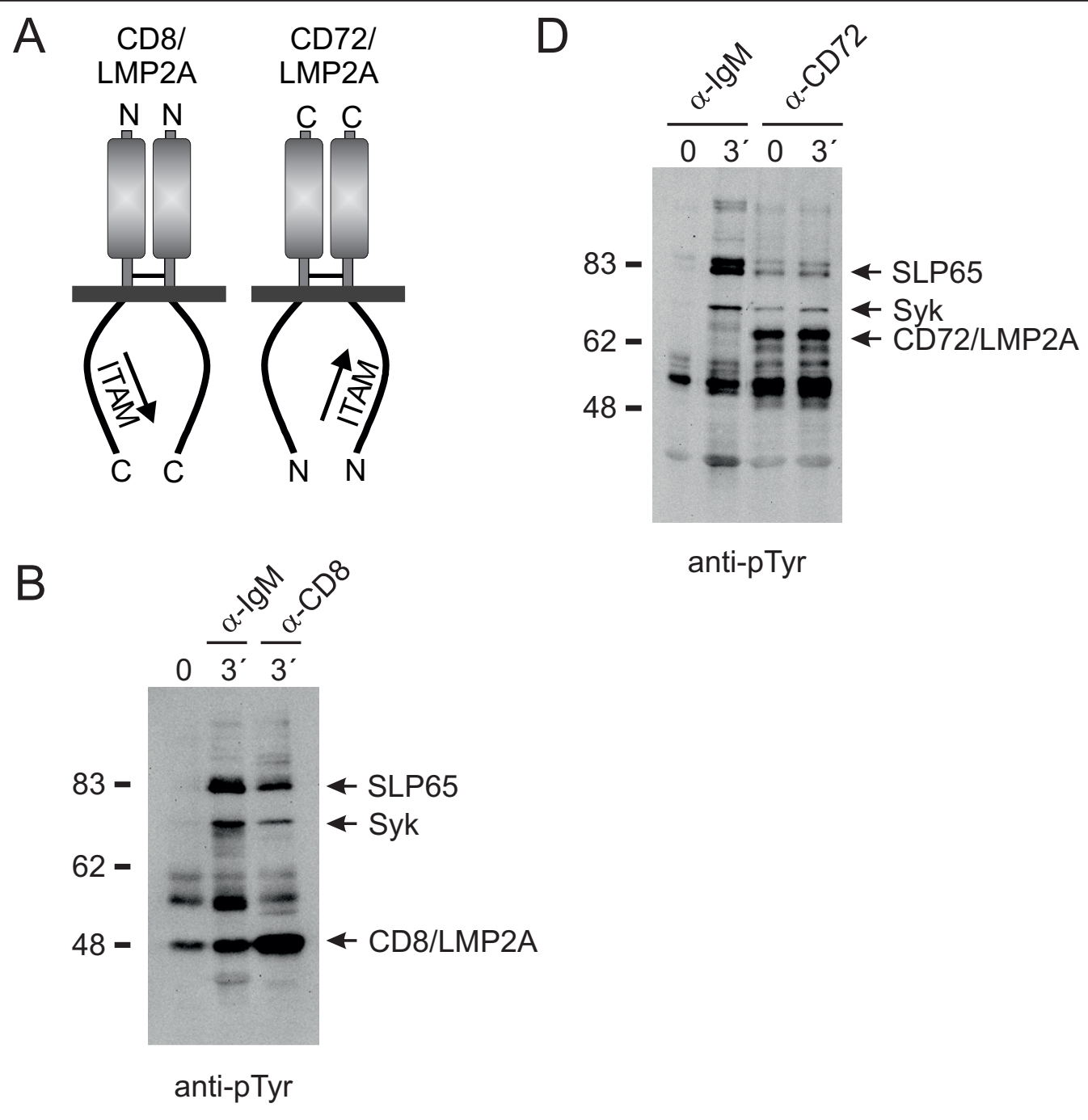

C

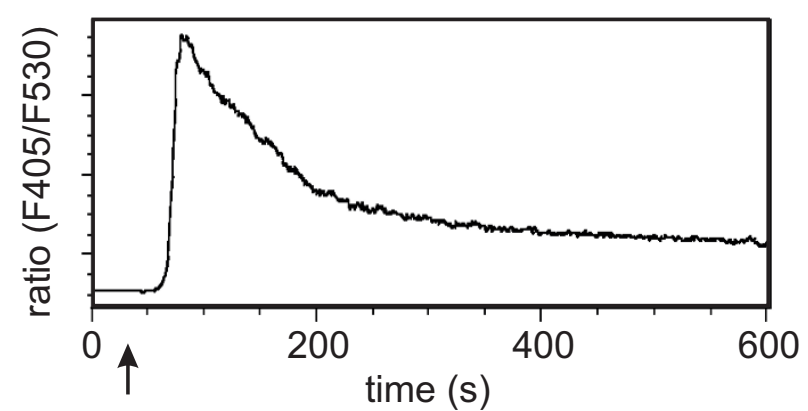

Figure 2 Stimulation-dependent versus autonomous signaling of the LMP2A-ITAM. (A) Schematic representation of CD8- and CD72-based transmembrane chimeras containing the cytoplasmic LMP2A N-terminus in type-I or type-II orientation, respectively. (B) DT40 transfectants, which constitutively express CD8/LMP2A were left unstimulated (lane 1) or stimulated for 3 min with either anti-lgM or anti-CD8 antibodies (lanes 2 and 3, respectively) and analyzed for PTK substrate phosphorylation by anti-phosphotyrosine immunoblotting as described in Figure 1C. Identification of Syk and SLP65 phosphoproteins was performed in separate experiments (data not shown). Relative molecular masses of marker proteins are indicated on the left in $\mathrm{kDa}$. (C) Indo-1-loaded CD8/LMP2A transfectants were stimulated with anti-CD8 antibodies (arrow) and mobilization of $\mathrm{Ca}^{2+}$ ions was monitored by flow cytometry. (D) DT40 transfectants, which were left uninduced (lanes 1-2) or treated with 4-HT for $6 \mathrm{~h}$ to induce expression of CD72/LMP2A (lanes 3-4) were analyzed for PTK substrate phosphorylation without stimulation (lanes 1 and 3) or after stimulation (lanes 2 and 4) with antibodies against IgM or CD72, respectively, by anti-phosphotyrosine immunoblotting as described in Figure 1C. 
LMP2A signaling mimics the activation signal of the BCR Having established that mere expression of LMP2A or its cytosolic N-terminus in its physiological orientation activates cytosolic PTKs, we next examined whether the signal chain proceeded to the PLC- $\gamma$-controlled generation of second messengers. Measurement of inositol-1,4,5-trisphosphate (IP3) amounts in resting, LMP2A-expressing or BCR-activated cells showed that LMP2A signaling induced considerably increased steady-state amounts of IP3 that reached about half of what was present at the peak of the BCR response (Figure $3 \mathrm{~A}$ ). Single cell $\mathrm{Ca}^{2+}$ flux analyses revealed that the elevated intracellular IP3 concentration gave rise to continuous cytosolic $\mathrm{Ca}^{2+}$ spikes (Figure 3B) that mirrored those observed approximately 15 min after the initial peak in long-term measurements of BCR-activated cells (Figure 3C). Again, analysis of the CD72/LMP2A fusion protein paralleled our findings with wild-type LMP2A (Figure 3D). In addition, the $\mathrm{Ca}^{2+}$ waves triggered by LMP2A were directly visualized by time lapse video imaging of Fluo-3-loaded cells (see Additional files 1, 2 and 3: Figure S1). The intensities of LMP2A-induced PTK activation and subsequent second messenger generation were sufficient to activate downstream signaling cascades such as the Erk MAP kinase pathway (Figure 4). Collectively, our data demonstrate that the LMP2A ITAM in its physiological membrane topology induces a ligation-independent activation signal during its initial expression that mimics that of the antigen-activated BCR.

\section{LMP2A signaling activates the EBV-encoded bzlf1 gene}

To assess further downstream responses as well as the functional significance of LMP2A-induced signals we monitored transcriptional activation of EBV-encoded bzlf1, which is the physiological trigger of the lytic replication cycle in EBV-infected host cells [17]. A reporter gene assay was established in which the entire bzlf1 locus including $\mathrm{pZ}$ promotor, open reading frame and two potential polyadenylation sites was transfected into DT40 cells. With this experimental setup we recapitulated the in vivo situation of EBV-infected cells in which BCRinduced BZLF1 protein stimulates transcription of its own promotor in a feed-forward loop [18]. Indeed, following BCR activation of the DT40 transfectants for 24 $\mathrm{h}, \mathrm{BZLF} 1$ protein production was detected by anti-BZLF1 immunoblotting (Figure 5A, lane 1). BZLF1 was also detectable following $16 \mathrm{~h}$ of 4-HT-mediated LMP2A induction and a maximum was reached after approximately 36 h (lanes 3-8). Note that, prior to feed-forward production of BZLF1, expression of LMP2A has to be induced for several hours by 4-HT treatment (see Figure 1) explaining the different kinetics of BCR-versus LMP2A-induced BZLF1 production. Likewise, the chimeric CD72/LMP2A protein, whose expression was induced with a faster kinetics than wild-type LMP2A (data not shown), triggered maximal BZLF1 production after induction for 20-28 h (Figure 5B). Mutational analysis of LMP2A signaling motifs showed that activation of the $\mathrm{pZ}$ promotor required a functional ITAM as exchange of its tyrosines to phenylalanine residues (Y74, 85 F) abrogated BZLF1 expression (Figure 5C, lanes 5-6). Inactivation of a non-ITAM tyrosine residue supposed to recruit the Src-family PTK Lyn (Y112F) only marginally affected LMP2A-induced production of BZLF1 (compare lanes 3-4 with 1-2). In contrast to the inducibly expressed LMP2A variants, the CD8/LMP2A fusion protein again required cross-linking with anti-CD8 antibodies to stimulate expression of BZLF1 in amounts similar to that achieved by the ITAMs of either Ig $\alpha$ or Ig $\beta$ (Figure 5D). Taken together, ligand independent LMP2A activation signals not only trigger cytosolic $\mathrm{Ca}^{2+}$ waves and MAP kinase activation but in addition to this translate into nuclear responses at the crossroad of latency versus lytic EBV replication.

\section{LMP2A modulates BCR signaling}

Early observations made in LCL suggested that LMP2A may exert an inhibitory effect on BCR proximal signaling events. To test this possibility we compared BCR-induced $\mathrm{Ca}^{2+}$ mobilization in $\mathrm{B}$ cells that did or did not express a constitutively active LMP2A ITAM (Figure 6). Since wildtype LMP2A was not detectable at the cell surface in our cells (data not shown) as reported for transiently transfected human B cells as well [19], we employed cells that were induced to express the CD72/LMP2A chimera. Expression of the chimera was detectable on the surface of live cells by staining with anti-CD72 antibodies (Figure 6A \&6B). This allowed us to compare the BCR-induced $\mathrm{Ca}^{2+}$ mobilization capacities of CD72/LMP2A-negative cells (blue lines) and CD72/LMP2A-positive cells (red lines).

Notably, the presence of the constitutively active LMP2A N-terminus drastically changed BCR-induced $\mathrm{Ca}^{2+}$ kinetics. While it delayed and dampened the peak of the response it caused a sustained, long-lasting increase in the cytosolic $\mathrm{Ca}^{2+}$ concentration compared with the relatively transient increase in wild-type cells. By contrast, crosslinking of CD72/LMP2A had only a minor effect on $\mathrm{Ca}^{2+}$ mobilization (Figure 6, purple lines). These data demonstrate that expression of the constitutively tyrosine phosphorylated LMP2A N-terminus can influence BCR proximal signaling mechanisms if both molecules get active in the same cell at the same time.

\section{Discussion}

With this report we reinforce the concept that LMP2A mimics BCR signal transduction $[15,16]$. The functional similarities are, however, not restricted to membrane-proximal signaling including PTK activation and 


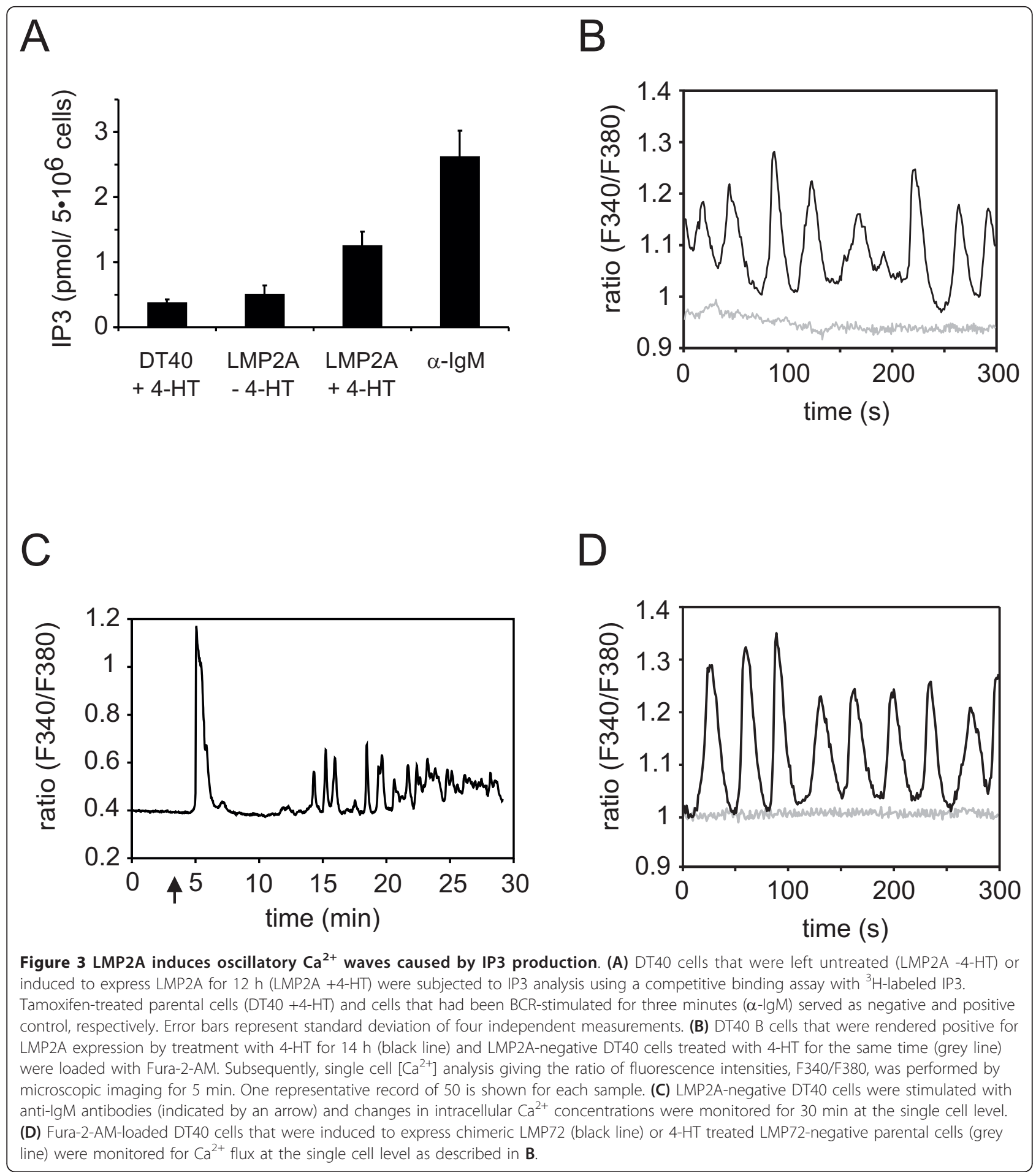

phosphorylation of SLP65 as previoulsy thought, but extend to cytosolic $\mathrm{Ca}^{2+}$ mobilization, activation of downstream signaling pathways and even nuclear responses such as activation of the EBV lytic gene bzlf1. These events are reminiscent of the antigeninduced BCR activation signal [7], which in fact represents a trigger of lytic EBV replication [20]. It thus appears that EBV possesses intrinsic and extrinsic modes for reactivation from latency, namely expression of and autonomous signaling by LMP2A as well as extracellular B cell stimulation through surface receptors such as the BCR. 


\section{MCM LMP2A \\ CD72/LMP2A

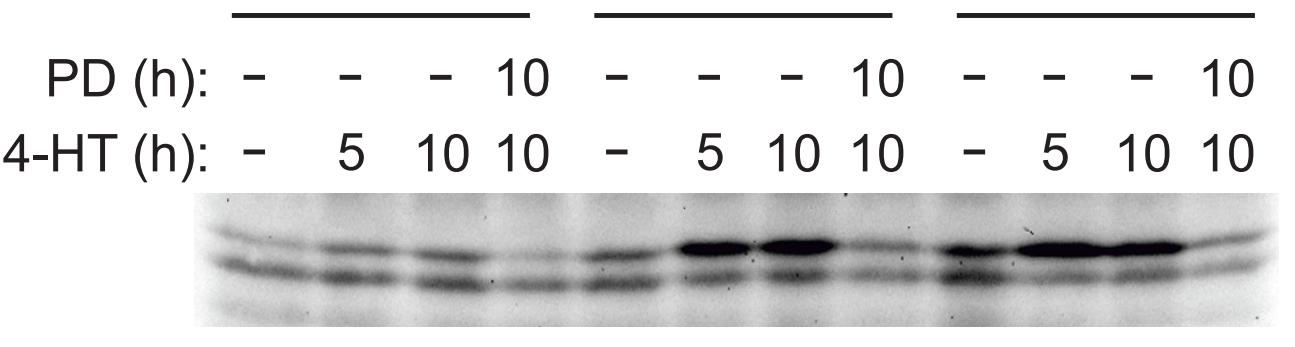 \\ anti-pErk}

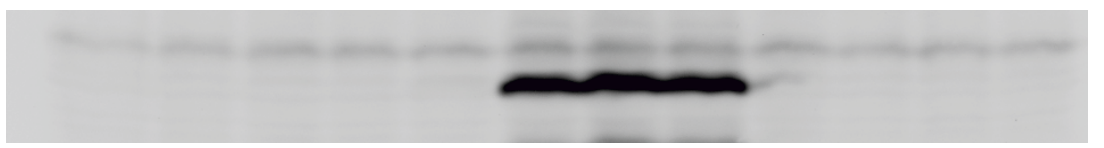

\section{anti-FLAG}

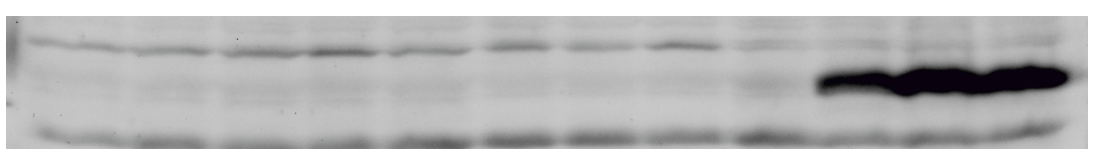

anti-CD72

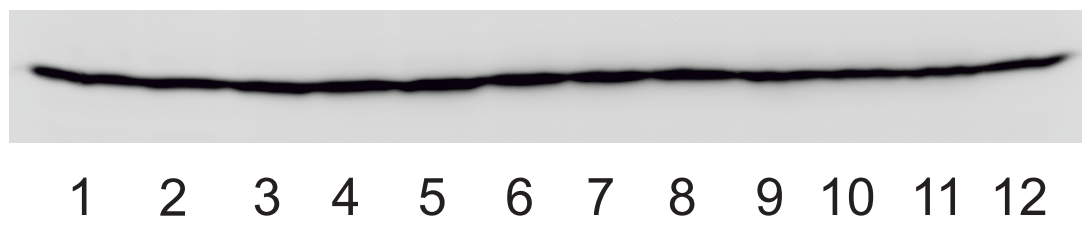

\section{anti-Erk}

\section{$\begin{array}{llllllllllll}1 & 2 & 3 & 4 & 5 & 6 & 7 & 8 & 9 & 10 & 11 & 12\end{array}$}

Figure 4 LMP2A expression activates the Erk MAP kinase cascade. DT40 cells were left untreated (lanes 1, 5 \& 9) or induced to express LMP2A (lanes 6-8) or CD72/LMP2A (lanes 10-12) for the indicated times in the absence or presence of 50 M PD98059 (PD, lanes 4, 8 \& 12). Parental cells served as control (MCM, lanes 1-4). Erk activation was monitored by immunoblot analysis of total cellular lysates with phospho-Erkspecific antibodies (upper panel). The membrane was sequentially re-probed with antibodies to the FLAG-tag, CD72 and Erk to demonstrate protein induction as well as equal protein loading.

The ligation-independent signaling capacity of LMP2A compelled us to employ an inducible expression strategy since permanent expression of the constitutively signaling LMP2A-ITAM was not endured by DT40 cells. The underlying molecular mechanisms that cause constitutive signaling of the LMP2A-ITAM remain elusive but are conserved in the type-II CD72/LMP2A fusion protein. This finding can explain the apparent discrepancy of studies made with chimeric type-I transmembrane proteins that required cross-linking with antibodies in order to signal and insights gained with full-length LMP2A in LCL.

The observed block of BCR signaling and bzlf1 transcription in LCL might be due to expression of additional EBV genes or a consequence of the cellular transformation process or both [21]. In LCL the latency type-III program is active, which normally operates only in proliferating EBV-positive B cells during infectious mononucleosis and post-transplantation lymphoproliferative disorders. This "EBV growth program" is characterized by the transcription of all EBV latency genes leading to the production of not only LMP2A but also LMP1, several Epstein-Barr nuclear antigens (EBNAs) as well as non-coding RNAs [22]. All of these molecules, perhaps in conjunction with the altered protein expression profile of transformed cells, may contribute to the particular LCL signaling phenotype. Furthermore, constant activation of BCR-regulated signal transducers leads to inhibitory feedback mechanisms that cause BCR unresponsiveness [13], a phenomenon that is most likely caused by continuous LMP2A expression alike. Nevertheless, our experiments show that the mere presence of the constitutively phosphorylated LMP2A N-terminus can modulate $\mathrm{BCR}$ proximal signaling events in non-anergic cells.

In the absence of a BCR, transgenic LMP2A expression can replace $B C R$ signaling required for the development and survival of peripheral $B$ cells $[5,23,24]$. As signaling for $\mathrm{B}$ cell survival requires a functional $\mathrm{Ca}^{2+}$ machinery, i.e. SLP65 as well as enzymatically active Btk and PLC- $\gamma 2$ [25-27], LMP2A must be able to trigger these molecules since otherwise it could not mediate development and maintenance of B cells in transgenic mice. As LMP2A signals autonomously without the need for extracellular ligation, it is most probably its amount produced in an individual cell that determines whether a maintenance signal or an activation signal is generated. Thus, moderate expression of LMP2A would drive B cell development and 


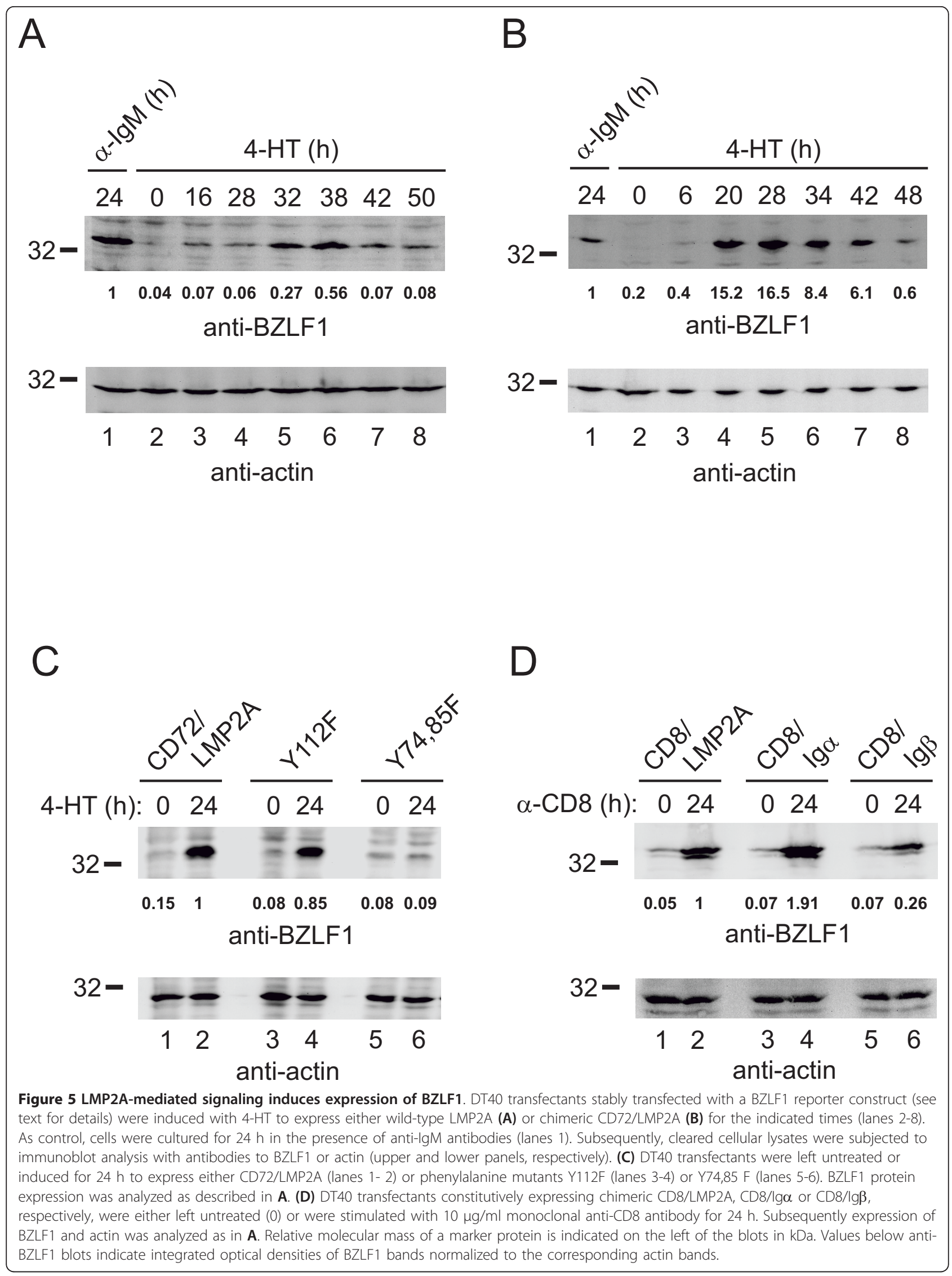



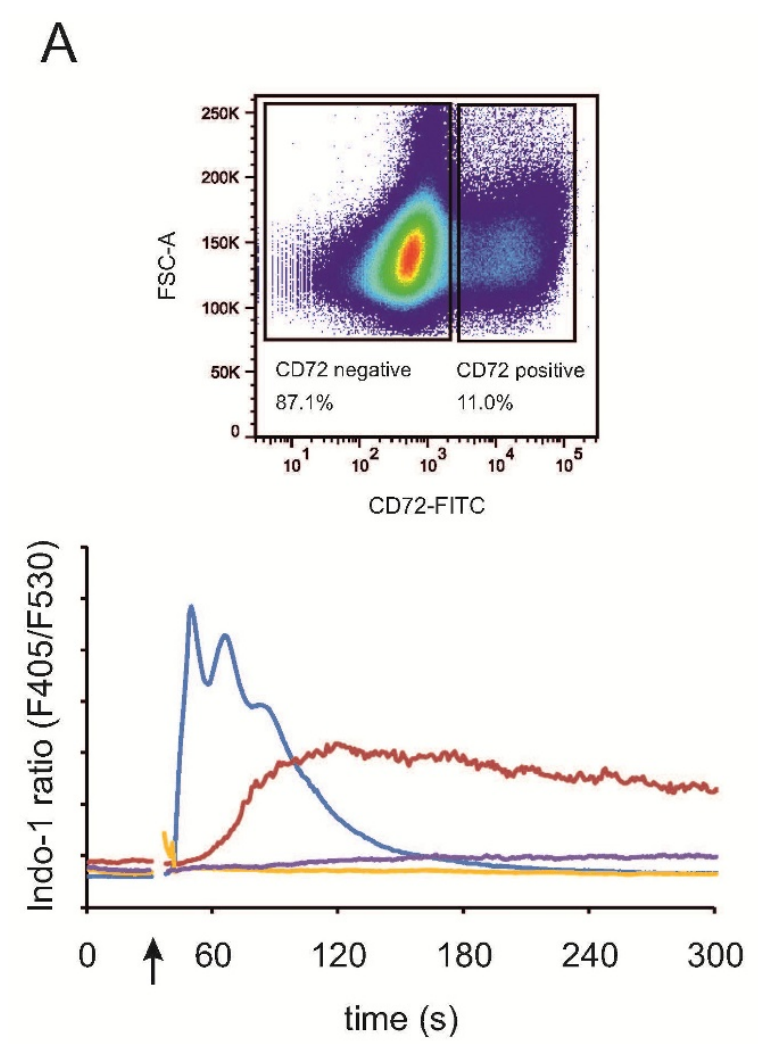

B
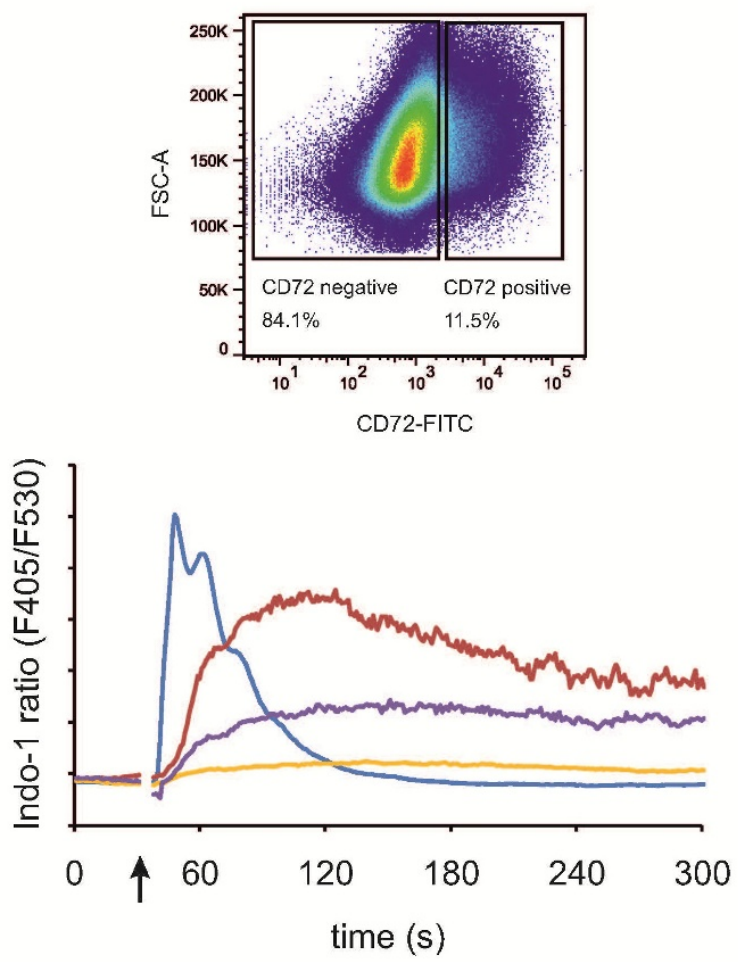

Figure 6 The LMP2A N-terminus modulates BCR signaling. DT40 transfectants were induced with 4-HT to express chimeric CD72/LMP2A, loaded with Indo-1 and stained with FITC-labeled anti-CD72 in order to gate on CD72 negative and CD72 positive cells (upper panels). Subsequently, BCR-induced $\mathrm{Ca}^{2+}$ responses were monitored by flow cytometry (lower panels) upon stimulation of the cells with anti-lgM antibodies (blue and red curves) or with anti-mouse lgG $\mathrm{F}(\mathrm{ab})_{2}$ fragments to super-crosslink the anti-CD72 antibody (purple and yellow curves). Blue and yellow lines represent CD72/LMP2A-negative cells, red and purple lines CD72/LMP2A-positive cells. (A) and (B) represent two indepent cell clones.

peripheral maintenance in transgenic mice as done by the unligated BCR. Elevated LMP2A expression by contrast mimics the activation signal of the antigen-stimulated BCR and leads to $\mathrm{Ca}^{2+}$ mobilization and production of BZLF1. Indeed, when LMP2A was transiently transfected into non-anergic EBV-positive B cells, it induced entry into the EBV lytic cycle, which is associated with production of BZLF1 and Virus Capsid Antigen [28]. This may induce lytic EBV replication and contribute to the onset of severe lymphoproliferative disorders that are often associated with EBV infection especially in immunocompromised hosts [29,30].

\section{Conclusion}

In conclusion, online monitoring of LMP2A expression and signaling in non-anergic $B$ cells uncovered an activation mechanism for virus-intrinsic regulation of lytic genes involving second messenger-controlled cellular signaling pathways. The autonomously activated signal chains can activate bzlf1 transcription and thereby render the lytic EBV replication cycle independent of extrinisic regulators. Moreover, the activation signal emanating from LMP2A is likely to contribute to EBVassociated lymphoproliferative disorders like Hodgkin lymphoma and post transplantation lymphomas.

\section{Methods}

\section{Plasmids and cDNAs}

The $l m p 2 a$ cDNA was amplified from an LCL (EBV strain B95-8). A triple FLAG-tag coding sequence was introduced by PCR into the coding sequence of the first extracellular loop resulting in LMP2A3xF which was ligated into pcDNA3 (Invitrogen) or pABESII. A puromycin resistance cassette flanked by two loxP sites was positioned between promotor and $\operatorname{lm} p 2 a 3 x F$ cDNA. Chimeric LMP2A/CD72 was generated by ligating the coding region of the LMP2A N-terminus (codons 1-121) to the coding sequence of transmembrane and extracellular parts of mouse CD72 (kindly provided by T. Tsubata, Tokyo, Japan). Chimeric CD8 constructs were generated alike (CD8 cDNA was kindly provided by B. Schraven, Magdeburg, Germany). The bzlf1 locus comprising 
promotor region (-221 onwards), open reading frame and two potential polyadenylation sites was PCR-amplified from an LCL (EBV strain B95-8) and ligated into pBS82HisD [31] carrying a histidinol resistance gene. Sequences of oligonucleotides are available upon request.

\section{Cells and antibodies}

MerCreMer-expressing DT40 cells (kindly provided by T. Brummer and M. Reth, Freiburg, Germany) were maintained in RPMI1640 + GlutaMAX (Invitrogen) supplemented with $10 \%$ FCS and $1 \%$ chicken serum. Translocation of MerCreMer to the nucleus was induced by addition of $200 \mathrm{nM}$ 4-hydroxytamoxifen (4-HT, Sigma, Munich, Germany). For stable transfections, $10^{7}$ cells suspended in ice-cold PBS containing $30 \mu \mathrm{g}$ of linearized expression vectors were electroporated using a Gene-Pulser (BioRad, Munich, Germany) $(260 \mathrm{~V}, 960 \mu \mathrm{F}$ in a 4 $\mathrm{mm}$ cuvette) and selected in the presence of $2 \mathrm{mg} / \mathrm{ml}$ G418, $1 \mathrm{mg} / \mathrm{ml}$ histidinol or $0.5 \mu \mathrm{g} / \mathrm{ml}$ puromycin, respectively. Monoclonal antibodies against BZLF1 (clone BZ.1) and human CD8 (MEM-31) were kind gifts of M. Rowe, Birmingham, UK or V. Horejsi, Prague, Czech Republic, respectively. Anti-FLAG (M2) was purchased from Sigma (Munich, Germany), anti-CD72 (K10.6) from BD Biosciences (Heidelberg, Germany), anti-phosphotyrosine (4G10) from Upstate (Biomol, Hamburg, Germany) and anti-phospho-Erk (E10) from CST (NEB, Frankfurt, Germany). Anti-chicken IgM antibody (M4) was purified from hybridoma supernatant. Prior to BCR stimulation, DT40 cells were starved for $30 \mathrm{~min}$ in RPMI without sera at $37^{\circ} \mathrm{C}$ and subsequently incubated with $3 \mu \mathrm{g} / \mathrm{ml} \mathrm{M} 4$.

\section{Protein analysis}

Cell lysis in 1\% NP-40 buffer and immunopurification of cellular proteins have been described previously [6]. For specific immunodetection of FLAG-tagged LMP2A $10^{6}$ cells were suspended in $30 \mu \mathrm{l}$ Laemmli buffer, incubated for $2 \mathrm{~min}$ at $75^{\circ} \mathrm{C}$ and homogenized by repeatedly passing through a 26 gauge needle. Immunoblots were developed with ECL (GE Healthcare, Freiburg, Germany) using a digital image acquisition system (Intas Chemilux Entry, Intas, Göttingen, Germany). Densitometric analysis of individual protein bands on immuno blots was carried out with GelPro Analyzer software (Media Cybernetics, Silver Spring, MD, USA).

\section{Ratiometric $\mathrm{Ca}^{2+}$ measurements and IP3 analysis}

$10^{6}$ DT40 cells were loaded with either $1 \mu \mathrm{M}$ Indo-1AM or $0.25 \mu \mathrm{M}$ Fura-2/AM (Molecular Probes) in RPMI containing $5 \%$ FCS and $0.015 \%$ pluronic acid at $30^{\circ} \mathrm{C}$ for $25 \mathrm{~min}$. Subsequently, the cell suspension was diluted 2-fold with RPMI $+10 \%$ FCS and incubated for $10 \mathrm{~min}$ at $37^{\circ} \mathrm{C}$. Cells were washed and resuspended in
Krebs Ringer solution composed of 10 mM HEPES ( $\mathrm{pH}$ 7.0), $140 \mathrm{mM} \mathrm{NaCl}, 4 \mathrm{mM} \mathrm{KCl}, 1 \mathrm{mM} \mathrm{MgCl}_{2}, 1 \mathrm{mM}$ $\mathrm{CaCl}_{2}$ and $10 \mathrm{mM}$ glucose. After monitoring basal $\left[\mathrm{Ca}^{2}\right.$ ${ }^{+}$] levels for $1 \mathrm{~min}$, cells were stimulated with $3 \mu \mathrm{g} / \mathrm{ml}$ M4. The ratio of $\mathrm{Ca}^{2+}$ bound vs. $\mathrm{Ca}^{2+}$ unbound Indo-1 fluorescence $(405 \mathrm{~nm} / 530 \mathrm{~nm})$ was monitored on an LSR II cytometer (Becton Dickinson). Single cell ratiometric $\left[\mathrm{Ca}^{2+}\right]$ measurements with Fura-2 were performed using an upright microscope (Axioskop 2, Zeiss, Göttingen, Germany) with a $40 \times / 0.9$ water immersion objective. Alternating excitation wavelengths at 340 and $380 \mathrm{~nm}$ were provided by a custom-built monochromator consisting of a Xenon lamp, a galvanometer-driven mirror, appropriate filters, and a shutter. Image pairs F340/F380 (alternating excitation at 340 and $380 \mathrm{~nm}$; emission $>505 \mathrm{~nm}$ ) of individual cells were taken at 0.5 $\mathrm{Hz}$ or $1 \mathrm{~Hz}$ using a frame-transfer, back-illuminated CCD camera (16 bits/pixel, Micromax; Visitron, Munich, Germany) and a custom-built monochromator. Images were acquired at $100 \mathrm{~ms}$ exposure time per image. Galvanometer, shutter as well as the CCD's acquisition and recording software (Winview, Visitron) were synchronized by a custom-built microcontroller programmed in $\mathrm{C}$ language. Image analysis was performed using custom programs written in MatLab (The MathWorks, Natick, MA). IP3 amounts from $5 \times 10^{6}$ cells were determined using the D-myo-Inositol 1,4,5-trisphosphate $\left[{ }^{3} \mathrm{H}\right]$ Biotrak Assay System (GE Healthcare, Freiburg, Germany) according to the manufacturers instructions.

\section{Additional material}

Additional file 1: Time Lapse Video Imaging of $\mathrm{Ca}^{2+}$ Flux in LMP2Aexpressing DT40 cells.

Additional file 2: Figure S1A.

Additional file 3: Figure S1B.

\section{Abbreviations}

4-HT: 4-hydroxytamoxifen; BCR: B cell antigen receptor; Btk: Bruton's tyrosine kinase; BZLF1: BamHI Z Leftward reading Frame 1; CIN85: Cbl-interacting protein of $85 \mathrm{kDa}$; Cre: crossover recombination; DAG: diacylglycerol; EBNA: Epstein-Barr nuclear antigen; EBV: Epstein-Barr virus; Erk: Extracellular signalregulated kinase; IP3: Inositol-1,4,5-trisphosphate; ITAM: Immunoreceptor tyrosine-based activation motif; LCL: Lymphoblastoid cell line; loxP: Locus of crossover in P1; LMP: Latent membrane protein; MAP: Mitogen-activated protein; MCM: MerCreMer; PLC-: Phospholipase C-; PTK: Protein tyrosine kinase; pTyr: Phospho-tyrosine; SLP65: SH2 domain-containing leukocyte protein of $65 \mathrm{kDa}$; Syk: Spleen tyrosine kinase

\section{Acknowledgements}

We wish to thank Drs. T. Brummer, M. Reth, M. Rowe, B. Schraven and T. Tsubata for reagents described in Methods and M. Müschen and M. Reppel for supporting $\mathrm{Ca}^{2+}$ flux analyses. Verena Schrader provided excellent technical assistance. This project was funded by the German Research Foundation (DFG) through FOR521 and by the DFG Center for Molecular Physiology of the Brain (Exc171, D.S.). 


\section{Author details}

${ }^{1}$ Institute of Cellular and Molecular Immunology, Georg-August-University Göttingen, Humboldtallee 34, Göttingen 37073, Germany. ${ }^{2}$ Institute of Neurophysiology and Cellular Biophysics, and DFG Center for Molecular Physiology of the Brain, Georg-August-University Göttingen, Humboldtallee 23, Göttingen 37073, Germany

\section{Authors' contributions}

NE designed the research, performed experiments and wrote the paper, GY and CE designed and performed experiments, DC and DS were involved in single cell $\mathrm{Ca}^{2+}$ flux analysis, JW supervised the project and wrote the paper. All authors read and approved the final manuscript.

\section{Competing interests}

The authors declare that they have no competing interests.

Received: 8 December 2011 Accepted: 3 April 2012

Published: 3 April 2012

\section{References}

1. Young LS, Rickinson AB: Epstein-Barr virus: 40 years on. Nat Rev Cancer 2004, 4:757-768

2. Kuppers R: B cells under influence: transformation of B cells by EpsteinBarr virus. Nat Rev Immunol 2003, 3:801-812.

3. Fruehling S, Longnecker R: The immunoreceptor tyrosine-based activation motif of Epstein-Barr virus LMP2A is essential for blocking BCR-mediated signal transduction. Virology 1997, 235:241-251.

4. Merchant M, Caldwell RG, Longnecker R: The LMP2A ITAM is essential for providing B cells with development and survival signals in vivo. J Virol 2000, 74:9115-9124.

5. Casola S, Otipoby KL, Alimzhanov M, Humme S, Uyttersprot N, Kutok JL, Carroll MC, Rajewsky K: B cell receptor signal strength determines B cell fate. Nat Immunol 2004, 5:317-327.

6. Engels N, Merchant M, Pappu R, Chan AC, Longnecker R, Wienands J: Epstein-Barr virus latent membrane protein 2A (LMP2A) employs the SLP-65 signaling module. J Exp Med 2001, 194:255-264.

7. Engelke M, Engels N, Dittmann K, Stork B, Wienands J: $\mathrm{Ca}(2+)$ signaling in antigen receptor-activated B lymphocytes. Immunol Rev 2007, 218:235-246.

8. Oellerich T, Bremes V, Neumann K, Bohnenberger H, Dittmann K, Hsiao HH, Engelke M, Schnyder T, Batista FD, Urlaub H, Wienands J: The B-cell antigen receptor signals through a preformed transducer module of SLP65 and CIN85. EMBO J 2011, 30:3620-3634.

9. Miller $\mathrm{CL}$, Lee $\mathrm{JH}$, Kieff E, Longnecker R: An integral membrane protein (LMP2) blocks reactivation of Epstein-Barr virus from latency following surface immunoglobulin crosslinking. Proc Natl Acad Sci USA 1994, 91:772-776.

10. Miller $C L$, Longnecker $R$, Kieff E: Epstein-Barr virus latent membrane protein 2A blocks calcium mobilization in B lymphocytes. J Virol 1993, 67:3087-3094.

11. Longnecker R, Miller CL: Regulation of Epstein-Barr virus latency by latent membrane protein 2. Trends Microbiol 1996, 4:38-42.

12. Gauld SB, Benschop RJ, Merrell KT, Cambier JC: Maintenance of B cell anergy requires constant antigen receptor occupancy and signaling. Nat Immunol 2005, 6:1160-1167.

13. Gauld SB, Merrell KT, Cambier JC: Silencing of autoreactive B cells by anergy: a fresh perspective. Curr Opin Immunol 2006, 18:292-297.

14. Zhang $Y$, Wienands J, Zurn C, Reth M: Induction of the antigen receptor expression on B lymphocytes results in rapid competence for signaling of SLP-65 and Syk. EMBO J 1998, 17:7304-7310.

15. Alber G, Kim KM, Weiser P, Riesterer C, Carsetti R, Reth M: Molecular mimicry of the antigen receptor signalling motif by transmembrane proteins of the Epstein-Barr virus and the bovine leukaemia virus. Curr Biol 1993, 3:333-339.

16. Beaufils $\mathrm{P}$, Choquet $\mathrm{D}$, Mamoun RZ, Malissen B: The (YXXL/I)2 signalling motif found in the cytoplasmic segments of the bovine leukaemia virus envelope protein and Epstein-Barr virus latent membrane protein $2 \mathrm{~A}$ can elicit early and late lymphocyte activation events. EMBO J 1993, 12:5105-5112.
17. Speck SH, Chatila T, Flemington E: Reactivation of Epstein-Barr virus: regulation and function of the BZLF1 gene. Trends Microbiol 1997, 5:399-405

18. Flemington E, Speck SH: Autoregulation of Epstein-Barr virus putative lytic switch gene BZLF1. J Virol 1990, 64:1227-1232.

19. Lynch DT, Zimmerman JS, Rowe DT: Epstein-Barr virus latent membrane protein $2 \mathrm{~B}$ (LMP2B) co-localizes with LMP2A in perinuclear regions in transiently transfected cells. J Gen Virol 2002, 83:1025-1035.

20. Tovey MG, Lenoir G, Begon-Lours J: Activation of latent Epstein-Barr virus by antibody to human IgM. Nature 1978, 276:270-272.

21. Adler B, Schaadt E, Kempkes B, Zimber-Strobl U, Baier B, Bornkamm GW: Control of Epstein-Barr virus reactivation by activated CD40 and viral latent membrane protein 1. Proc Natl Acad Sci USA 2002, 99:437-442.

22. Thorley-Lawson DA: Epstein-Barr virus: exploiting the immune system. Nat Rev Immunol 2001, 1:75-82.

23. Caldwell RG, Wilson JB, Anderson SJ, Longnecker R: Epstein-Barr virus LMP2A drives B cell development and survival in the absence of normal B cell receptor signals. Immunity 1998, 9:405-411.

24. Ikeda A, Merchant M, Lev L, Longnecker R, Ikeda M: Latent membrane protein $2 \mathrm{~A}$, a viral $\mathrm{B}$ cell receptor homologue, induces CD5+ B-1 cell development. J Immunol 2004, 172:5329-5337

25. Khan WN, Alt FW, Gerstein RM, Malynn BA, Larsson I, Rathbun G, Davidson L, Muller S, Kantor AB, Herzenberg LA, et al: Defective B cell development and function in Btk-deficient mice. Immunity 1995 , 3:283-299.

26. Hashimoto A, Takeda K, Inaba M, Sekimata M, Kaisho T, Ikehara S, Homma Y, Akira S, Kurosaki T: Cutting edge: essential role of phospholipase C-gamma 2 in B cell development and function. $J$ Immunol 2000, 165:1738-1742.

27. Wang D, Feng J, Wen R, Marine JC, Sangster MY, Parganas E, Hoffmeyer A, Jackson CW, Cleveland JL, Murray PJ, Ihle JN: Phospholipase Cgamma2 is essential in the functions of B cell and several Fc receptors. Immunity 2000, 13:25-35.

28. Schaadt E, Baier B, Mautner J, Bornkamm GW, Adler B: Epstein-Barr virus latent membrane protein $2 A$ mimics B-cell receptor-dependent virus reactivation. J Gen Virol 2005, 86:551-559.

29. Gottschalk S, Rooney CM, Heslop HE: Post-transplant lymphoproliferative disorders. Annu Rev Med 2005, 56:29-44.

30. Mancao C, Hammerschmidt W: Epstein-Barr virus latent membrane protein $2 \mathrm{~A}$ is a B-cell receptor mimic and essential for B-cell survival. Blood 2007, 110:3715-3721.

31. Stork B, Engelke M, Frey J, Horejsi V, Hamm-Baarke A, Schraven B, Kurosaki T, Wienands J: Grb2 and the non-T cell activation linker NTAL constitute a $\mathrm{Ca}(2+)$-regulating signal circuit in $\mathrm{B}$ lymphocytes. Immunity 2004, 21:681-691.

doi:10.1186/1478-811X-10-9

Cite this article as: Engels et al:: Epstein-Barr virus LMP2A signaling in statu nascendi mimics a B cell antigen receptor-like activation signal. Cell Communication and Signaling 2012 10:9.

\section{Submit your next manuscript to BioMed Central and take full advantage of:}

- Convenient online submission

- Thorough peer review

- No space constraints or color figure charges

- Immediate publication on acceptance

- Inclusion in PubMed, CAS, Scopus and Google Scholar

- Research which is freely available for redistribution

Submit your manuscript at www.biomedcentral.com/submit
C Biomed Central 